\title{
Advances in the Management of Sleep Disorders in Juvenile Myoclonic Epilepsy
}

\author{
Polina V. Moskaleva ${ }^{1}$; Olga S. Shilkina ${ }^{1}$; Natalia A. Shnayder, PhD, ScD ${ }^{1,2^{*}}$; \\ Ivan P. Artyukhov, $\mathrm{PhD}, \mathrm{ScD}^{1}$; Diana V. Dmitrenko, $\mathrm{PhD}, \mathrm{ScD}^{1}$; Elena A. Yuryeva, $\mathrm{PhD}^{1}$ \\ ${ }^{1}$ V.F. Voino-Yasenetsky Krasnoyarsk State Medical University Krasnoyarsk, Krasnoyarsk, Russia \\ ${ }^{2}$ St. Petersburg V.M. Bekhterev Psychoneurological Research Institute, St. Petersburg, Russia
}

\begin{abstract}
Juvenile myoclonic epilepsy (JME) is a well-defined sub-syndrome of idiopathic generalized/genetic epilepsy, usually presenting in adolescence and characterized by myoclonic jerks, predominately in the arms, associated with tonic-clonic seizures and less often generalized absences. Although the evidence base for a relationship between JME and sleep disorders is weak, most experts regard sleep disorders as an actual comorbidity. This paper reviews the literature underpinning the development of sleep disorders in JME patients. Data that report associated causes of sleep problems in JME patients are discussed, as is the importance of counseling on lifestyle issues. Lastly, a practical approach to managing sleep disorders in young men and women with JME is summarized. (International Journal of Biomedicine. 2018;8(2):108-114.)
\end{abstract}

Key Words: juvenile myoclonic epilepsy $\bullet$ sleep $\bullet$ comorbidity $\bullet$ managment

\section{Abbreviations}

AEDs, antiepileptic drugs; EEG, electroencephalography; GABA, gamma-aminobutyric acid; JME, juvenile myoclonic epilepsy; NREMS, non-rapid eye movement sleep; PDs, personality disorders; PSG, polysomnography; QL, the quality of life; REMS, rapid eye movement sleep; SDs, sleep disorders; TLE, temporal lobe epilepsy.

\section{Introduction}

Sleep is a naturally recurring state of mind and body, characterized by altered consciousness, relatively inhibited sensory activity, inhibition of nearly all voluntary muscles, and reduced interactions with surroundings. ${ }^{(1)}$ Sleep is a necessary condition for the normal functioning of the brain. Even the loss of one hour of sleep time that accumulates for several days can have a powerful negative effect on daytime performance, thinking, and mood. After one night of total sleep deprivation, even healthy people scored significantly lower on tests of judgment, simple reaction time, explicit recall, and inverse word reading. ${ }^{(2)}$ Moreover, the brain has a

*Corresponding author: Prof. Natalia A. Shnayder, PhD, ScD; Leading Researcher, Department of Personalized Psychiatry and Neurology, St.Petersburg V.M. Bekhterev Psychoneurological Research Institute, Russia. E-mail: nataliashnayder@gmail.com neurophysiological pathology that is more dependent on sleep than on health.

Epilepsy and sleep disorders (SDs) are closely connected. B.Schmitt showed that about $20 \%$ of patients suffer seizures only at night, approximately $40 \%$ only during the day and approximately $35 \%$ during day and night. ${ }^{(3)}$ That is more than half of patients have nocturnal seizures during sleep.

Currently, scientists are trying to relate certain epilepsies with different SDs: disturbance of sleep quality and architecture, daytime sleepiness, and others. Chronobiology and chronopharmacology of epilepsy are actively developing scientific directions. ${ }^{(4)}$

Seizures and AEDs can lead to different SDs and, conversely, SDs can cause daytime sleepiness, memory impairment, and loss of control of seizures in epileptic patients. ${ }^{(5)}$ Depression, anxiety, and suicidal ideation are also considered as causes of secondary chronic insomnia-sleep 
disorder characterized by an inability to sleep or to remain asleep for a reasonable period-and hence they may also cause impairments in daily regime and mode of the drugs. ${ }^{(4)}$ These relationships are shown in Figure 1.

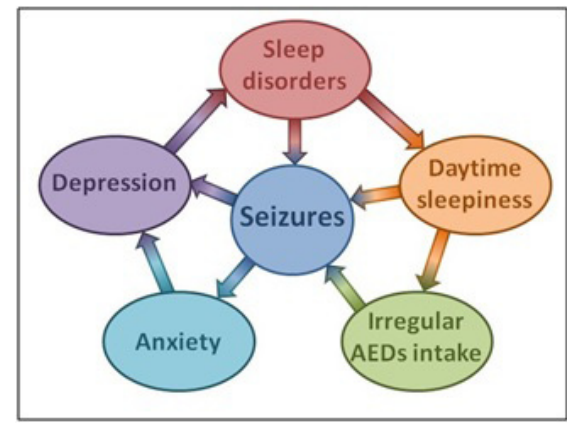

Fig. 1. Interference of seizures and sleep in $J M E$ patients.

These problems are more common in JME, which is characterized by frequent myoclonic jerks, most often of the upper limbs, usually occurring shortly after awakening; possible generalized tonic-clonic seizures; and absences. ${ }^{(6)}$

Dr Gary J Dennis divided the focal forms of epilepsies into seizures arising from sleep and idiopathic generalized/ genetic epilepsies, which include JME, when seizures arise shortly before or after sleep onset but not from a sleep stage (Table 1). ${ }^{(7)}$

Table 1.

Epilepsy syndromes closely associated with sleep (7)

\begin{tabular}{|l|l|l|}
\hline \multicolumn{1}{|c|}{ Focal onset syndromes } & \multicolumn{1}{|c|}{$\begin{array}{c}\text { Idiopathic } \\
\text { generalized } \\
\text { epilepsy syndromes }\end{array}$} & $\begin{array}{c}\text { Epilepsy } \\
\text { of uncertain origin } \\
\text { of unce }\end{array}$ \\
\hline $\begin{array}{l}\text { Benign childhood epilepsy } \\
\text { with centrotemporal spikes } \\
\text { (BCECTS or Rolandic } \\
\text { epilepsy) }\end{array}$ & JME & $\begin{array}{l}\text { Continuous spike } \\
\text { and wave during } \\
\text { slow wave sleep }\end{array}$ \\
\hline $\begin{array}{l}\text { Begin childhood epilepsy } \\
\text { with occipital paroxysms } \\
\text { (Panayiotopoulos } \\
\text { syndrome) }\end{array}$ & $\begin{array}{l}\text { Generalized tonic- } \\
\text { clonic seizures on } \\
\text { waking }\end{array}$ & $\begin{array}{l}\text { Landau-Kleffner } \\
\text { syndrome }\end{array}$ \\
\hline $\begin{array}{l}\text { Autosomal dominant } \\
\text { nocturnal frontal lobe } \\
\text { epilepsy (ADNFL) }\end{array}$ & & \\
\hline $\begin{array}{l}\text { Nocturnal frontal lobe } \\
\text { epilepsy }\end{array}$ & & \\
\hline $\begin{array}{l}\text { Nocturnal temporal lobe } \\
\text { epilepsy }\end{array}$ & & \\
\hline
\end{tabular}

Important provokers of seizures in JME were: (1) in $83 \%$ of patients, a disturbance in the circadian rhythm of sleep, (2) in $77 \%-80 \%$ of patients, sleep deprivation, and (3) in $66 \%$, fatigue. ${ }^{(8,9)}$

Abnormalities in frontal lobe gray matter, often occurring with JME, lead to psychological changes in personality:
Namely, dysfunction of frontal lobes, especially the prefrontal cortex, results in deficits of executive functions, including concept formation, abstract reasoning, and planning as well as self-regulation of behavior and control of impulsivity and emotions. Executive functions are responsible for processes of the elaboration of cognitive and behavioral reactions and strategies for the achievement of immediate or future goals. ${ }^{(10,11)}$

This feature can explain the failure of IME patients to follow treatment recommendations and regulate their sleep habits. ${ }^{(4)}$

\section{Diagnostics of sleep disorders}

The uses of EEG and PSG for evaluating sleep quality and its architecture in JME patients are described in the scientific literature.

\section{$\underline{1 . E E G}$}

Interictal EEG abnormalities were reported in $76 \%-88 \%$ of cases. ${ }^{(12,13)}$ JME is usually associated with a generalized 4to 6-Hz polyspike and wave, and less commonly with single spikes or sharp waves..$^{(9)}$ Several scientists also describe subtle focal EEG abnormalities and other peculiar EEG characteristics in JME patients. ${ }^{(14)}$ These EEG patterns are likely registered during NREM sleep, while REM sleep is resistant to their propagation. ${ }^{(15)}$ So such electroencephalographic potentials clinically manifest in arousals and sleep fragmentation, ending with episodic daytime sleepiness. This closes the vicious cycle because sleep deprivation is a trigger for seizures and epileptiform discharges. ${ }^{(16)}$

\section{2. $P S G$}

All-night polysomnographic recordings are used for analyzing epileptiform EEG abnormalities in relation to sleep stages. ${ }^{(17)}$ It has been demonstrated ${ }^{(16,18)}$ that epileptiform discharges in NREMS, leading to arousal, form stage shifts.Several studies have evaluated such sleep parameters as sleep duration, sleep onset latency, sleep staging, wakefulness after sleep onset, sleep efficiency, REMS latency and duration, arousal index, apnea-hypopnea index, cardiac events, and periodic limb movements during sleep. ${ }^{\left({ }^{16)}\right.}$

Sleep instability (difficulties in initiation and maintenance of sleep) in JME patients was confirmed in many studies. According to research by P.Kristian et al., ${ }^{(19)}$ which was confirmed by others, ${ }^{(16)}$ patients had reduced sleep efficiency, increased sleep onset latency, and increased wake percentage. Reduced REMS was noted by S.Roshan up to the total lack of REMS at all during sleep cycles. ${ }^{(16)}$

The purpose of this review was to evaluate scientific literature on management of SDs in JME.

\section{Materials and Methods}

Available full-text publications were selected from the following databases: PubMed, Springer, Clinical Keys, and eLIBRARY.RU. The search for publications was conducted using the following keywords: "Juvenile myoclonic epilepsy" and "sleep disorders." We considered studies published from 1992 to 2017 and identified 48 publications dealing with the problem of the influence of sleep on JME. Only 12 of these 
publications have been included in this review, based on search criteria.

\section{Results}

Our analysis shows that there is a bi-directional connection between JME and SDs. High-grade healthy sleep is one of the keys to successful control of seizures. However, there is a reverse effect of epilepsy on sleep. In this scientific review, we highlighted the three main reasons for SDs in JME:

1. The epilepsy itself

2. The lifestyle of patients

3 . The comorbid depression and anxiety

4. The application of AEDs

\section{The epilepsy itself}

The peak of JME onset is between ages 14 and 16, with a diapason from 8 to 25 years (i.e. transitional age) when it is especially difficult to find an approach to the patient.

Sleep deprivation, as the most common predictor for seizures, can follow from stress, menstruation in females, sounds, and alcohol consumption. ${ }^{(16)}$ These are precisely the unfavorable factors facing a patient-teenager, besides JME.

JME is a socially significant disease with poor long-term social outcome after 25 years, including depression, social isolation, and underemployment. ${ }^{(20-22)}$ Such young patients usually have difficulties with socialization, and sometimes even demonstrate agoraphobic disorders. The debut of the disease is often accompanied by a negative attitude and unwillingness to follow the doctor's recommendations. Patients deal with the problems of socialization by, for example, going to nightclubs where they face most of the dangerous factors of sleep deprivation and seizures described above. It is important that doctors should not require applying restrictions, because excessive regimentation may be counterproductive. ${ }^{(3)}$ In addition, the formation of the menstrual cycle in girls, which is also a proconvulsant, plays an important role at this time.

Because JME is a chronic disease, the circadian rhythm and circadian profile are very important. A.Fukuda compared JME with TLE and concluded that the pattern of seizure occurrence in JME patients tends to be on awakening (diurnal seizures), while TLE patients tend to have seizures during sleep (nocturnal seizures). Consequently, Fukuda and colleagues suggested that most JME patients do not feel better in the morning, especially if there was a lack of sleep the day before. ${ }^{(23)}$ Thus, disturbances of the regime cause seizures, resulting in daytime sleepiness, which in turn leads again to disturbances of regime. The doctor can break this triangle only by establishing individual contact and trust with every patient.

\section{The lifestyle of patients}

Counseling patients on the importance of adequate sleep hygiene and alcohol restriction is an important part of the management strategy for JME patients, but information is lacking on how these lifestyle restrictions impact JME patients. In one study, however, Leahy et al. conducted a qualitative descriptive analysis of the social impact of JME on patients, from their own perspective. ${ }^{(24)}$ The researchers identified four prominent themes: the importance of alcohol use as a social norm, how JME affected relationships, decision making (risk versus consequences), and knowledge-imparting control. Given that these restrictions were interpreted by patients as social curfews, we suggest that the term "Cinderella Syndrome" encapsulates the perceived imperative to be home before midnight. These findings underscore the importance for clinicians to recognize that in counseling patients with JME about lifestyle adjustments, there may be a significant social consequence unique to this patient group. So reinforcement of proper behavior and sleep hygiene should be encouraged by doctors and family members to help control of seizure in JME patients. ${ }^{(23)}$

There are several key points of education and support of JME patients. ${ }^{(25)}$ The patient with JME needs support first in the family in which he grows, and then in the family which he creates. At the first stage, after the debut of the disease, parents need to help the child take the disease and understand how to live with it. The teenager should know about safety and mortality risks, healthy lifestyle, and potential comorbidities to be able to assess his condition and well-being. Parents, in turn, should not only support the child, but also create a favorable environment: social (prevention of aggravation and agoraphobia, teacher and collective notification), psychological (support groups, stigmas destruction), and physical (organization of safe leisure and healthy sleep).

An equally important stage for the JME patient is the transition to adulthood, because JME is a chronic disease. The patient begins to conduct self-control and self-determination. The development of relationships with the opposite sex should preferably be sincere and mutual. It is necessary to inform the person who spends a lot of time with the patient about the possibility of seizures and their causes, so that the reason for refusing alcohol or the need for early sleep, for example, will be clear. This will help avoid conflicts, and hence stress, for the patient. It is important to remember about contraception to avoid a shock due to unwanted pregnancy. Therefore, it is necessary to strictly observe the sleep-wakefulness regime, and explain to the partner this need. It is necessary to find a compromise between the restrictions narrowing the life of a person with epilepsy and the possibility of a full life.

\section{Comorbid depression and anxiety}

As well as being a very common neurological disease worldwide, epilepsy significantly impairs patients' emotional, behavioral, and cognitive functioning. SDs are the most frequent complaint in patients with epilepsy. Adults with epilepsy have poorer self-reported subjective sleep quality and a higher prevalence of insomnia than the control group. Depressive and anxiety-related symptoms independently exert an adverse effect on the subjective sleep quality and insomnia of patients. In addition, seizure control, partial seizures, and the duration of epilepsy affect the quality of sleep and insomnia in patients, but seem less powerful predictors of sleep quality and insomnia than affective symptoms. Early identification and treatment of affective symptoms is of great importance in improving the sleep quality and insomnia of patients with epilepsy. ${ }^{(26)}$ 
The difficulty of establishing contact is due to comorbid depression. Lack of drive and endurance, unstable selfconcept, and rapidly changing affect and mood states are typical features of JME patients. ${ }^{(27)}$ The social-cultural background of patients, rather than neurobiological factors, may be a reason for SDs ${ }^{(23)}$ and for the depression and anxiety often described in JME. ${ }^{(28-30)}$

Sh.Somayajula et al. ${ }^{(31)}$ studied PDs, psychosocial and socioprofessional integration, in 165 JME patients. Of those, $77 / 46.7 \%$ patients were diagnosed with PDs, while 50/30.3\% (more common in young people) were categorized as having anxiety disorders, and $27 / 16.4 \%$ patients (more common in the elderly) had depressive disorders.

Insomnia is the cause of the depression and personality traits of JME patients. Moskaleva et al. previously described this vicious cycle: "Despite recognizing the factors, which cause more frequent seizures and worsening of the general condition, many patients cannot cope with their emotions singly; they note a decrease in stress resistance, and therefore complain about the difficulties of falling asleep, resulting in an undesirable lack of sleep."(32)

Depression forms pathophysiological pathways with the epileptogenic process and may be independent of seizure control. S.Roshan tried to attribute this connection. He observed that the GABRA1 gene on chromosome 5q and the GABRD gene on chromosome $1 \mathrm{p}$ are two of the genes responsible for JME pathogenesis ${ }^{(33)}$ and, on the other hand, GABA is a crucial mediator of sleep architecture. «The effect of defective GABA receptors is the loss of inhibitory signals with resultant increase in the cortical excitability». So the GABAergic pathway may be the reason for both the disease and its comorbidities. ${ }^{(16)}$

\section{The application of AEDs}

Previous work has shown that sleep deprivation of any type can exacerbate seizure activity, leading to speculation that the intrinsically poor sleep in these patients may serve as a threshold-lowering factor, and that this factor might be partially reversed by effective AEDs. However, to better understand this interaction, it is necessary to know whether the sleep disorder of JME is caused by repetitive ictal events or whether it is part of a process that causes epilepsy to emerge in the first place. ${ }^{(34)}$ On the contrary, SDs can be a consequence of taking the AEDs (Table 2). There are 3 criteria: mono/poly therapy, dose, type of AEDs.

\section{Mono/poly therapy}

B.Vaughn claimed that excessive daytime sleepiness is associated with low seizure control and with monotherapy with low AEDs serum levels. ${ }^{(35)}$ Foldvary-Schaefer demonstrated the same facts with an emphasis on the fact that SDs often need to be suspected in patients with daytime sleepiness and well-controlled seizures (i.e. taking AED monotherapy or low serum drug concentrations). ${ }^{(36)}$

$\underline{\text { Dose }}$

S.Roshan et al. concluded that the quality and architecture of sleep are disturbed predominantly by the disease itself, with some additional contribution of AEDs, because comparing the results of patients on drugs and a drug naive group, they did not identify a statistically significant difference in most of the sleep parameters, except a reduced percentage of slow-wave sleep (N3) in the drug treatment group. ${ }^{(16)}$ Similar results not distinguishable between drug-naive and valproate-groups were shown by Ramachandraiah and colleagues: higher epileptiform discharges in N1/REM in the drug-naive group; higher

Table 2.

Effects of AEDs on sleep

\begin{tabular}{|c|c|c|}
\hline \multirow{2}{*}{ AEDs } & \multicolumn{2}{|c|}{ Influences on sleep } \\
\hline & Sedative effects - positive $(+)$ & Negative (-) effects \\
\hline \multicolumn{3}{|c|}{ First-generation drugs } \\
\hline \multicolumn{3}{|l|}{ First choice line drugs } \\
\hline Valproates & $\begin{array}{l}\text { beneficially modulate arousal instability }{ }^{(44)} \\
\text { mood stabilizing } \rightarrow \text { relief from depression and } \\
\text { exclusion of nREM parasomnias }{ }^{(7)}\end{array}$ & $\begin{array}{l}\rightarrow \text { sleepiness } \\
\rightarrow \text { depression }\end{array}$ \\
\hline \multicolumn{3}{|c|}{ Second choice line drugs (combined therapy) } \\
\hline $\begin{array}{l}\text { Succinimides (Phenytoin, } \\
\text { Ethosuximide) }(37,38)\end{array}$ & \multirow{4}{*}{$\rightarrow$ normalization of the sleep in patients with insomnia ${ }^{(23)}$} & $\begin{array}{l}\rightarrow \text { a decrease in delta sleep and an increase } \\
\text { in stage } 1 \text { nREMS }{ }^{(43)}\end{array}$ \\
\hline Barbiturates (Phenobarbital) ${ }^{(38)}$ & & $\rightarrow$ sleepiness \\
\hline $\begin{array}{l}\text { Benzodiazepines (Clonazepam, } \\
\text { Clobazam) }{ }^{(41,42)}\end{array}$ & & $\begin{array}{l}\rightarrow \text { sleepiness } \\
\rightarrow \text { episodes of nocturnal apnoea }{ }^{(45)}\end{array}$ \\
\hline Iminostilbenes (Carbamazepine) ${ }^{(40)}$ & & $\rightarrow$ anxiety \\
\hline \multicolumn{3}{|c|}{ Second-generation drugs } \\
\hline Levetiracetam & & $\underset{\text { irritability }}{\rightarrow}$ fatigue, sleepiness, ${ }^{(7)}$ nervousness, \\
\hline Lamotrigine & $\begin{array}{l}\text { mood stabilizing } \rightarrow \text { relief from depression and exclusion } \\
\text { of nREM parasomnias }{ }^{(7)}\end{array}$ & $\rightarrow$ dose-dependent insomnia ${ }^{(43)}$ \\
\hline Topiramate & $\begin{array}{l}\text { weight control and mood stabilizing } \rightarrow \text { exclusion of } \\
\text { obstructive sleep apnoea }^{(7)}\end{array}$ & \\
\hline
\end{tabular}


epileptiform discharges in $\mathrm{N} 2 / \mathrm{N} 3$ in the valproate group. ${ }^{(18)}$ Krishnan and colleagues found a longer stage 2 and N3 latency in JME patients on valproate therapy $>1$ year. ${ }^{(19)}$ Therefore, valproate in higher dosages and longer treatment disrupts slow-wave sleep and increases shallow or light (N2) GABA sleep. ${ }^{(16)}$

\section{Type of AEDs}

There are a few AEDs that promote stabilization and normalization of sleep, such as phenytoin, ${ }^{(23,37,38)}$ carbamazepine, ${ }^{(23,39,40)}$ and benzodiazepines. ${ }^{(23,41,42)}$ On other hand, there are sedative AEDs that may increase sleepiness, such as clobazam, clonazepam and phenobarbital. Lamotrigine may cause dose-dependent insomnia. ${ }^{(43)}$ Ethosuximide decreases slowwave sleep and increases stage 1 nREMS. ${ }^{(43)}$ Valproates may beneficially modulate arousal instability in JME patients. ${ }^{(44)}$

The effects of the more recently introduced AEDs on sleep in JME patients await further investigations. With the large number of AED choices currently available, and with additional AEDs in clinical testing, clinicians may base their AED choice not only on JME manifestation, but also on its effects on sleep. For example, sedating AEDs may benefit epilepsy patients with insomnia, and stimulating AEDs may benefit epilepsy patients with daytime sleepiness. In addition to their direct pharmacologic effects on sleep, AEDs may indirectly improve sleep in the epilepsy patient through the reduction of seizures and, in some cases, interictal epileptic discharges.

\section{Discussion}

JME is among the most common types of genetic epilepsies, displaying a good prognosis when treated with appropriate drugs, but with a well-known tendency to relapse after withdrawal. The majority of JME patients have continuing seizures after a follow-up of two decades. ${ }^{(46)}$ However, the clinical scenario might not be as clear as the classical description would suggest. Repeated mistakes in diagnosis and treatment of JME are a problem of management and continuity of patient management among physicians in primary health care. ${ }^{(47)}$ Delayed diagnosis (and/or misdiagnosis) of JME directly impacts the development of the disease. Inadequate treatment allows aggravation of seizures and worsening of the condition, alongside undesired side effects and emotional stress, all of which significantly reduce patients' quality of life. ${ }^{(48)}$ Clinicians should remember that there is a small but still considerable subgroup of JME patients whose seizures are difficult to treat before informing patients with newly diagnosed JME about their "benign" prognosis. This resistant course is not fully explained, though there are many suggested factors. ${ }^{(46)}$ Usually, the dominating myoclonic seizures do not disappear nor diminish in severity in JME patients with SDs. Despite the favorable JME outcome in most of the cases, $75 \%$ of JME patients have at least one major unfavorable social outcome. The possible subsyndromes of JME, ${ }^{(49)}$ and sleep pathophysiological/neurophysiological correlates should be further investigated.

The relationship between JME and sleep has been known since ancient times, but it is still not very well understood because of the multiple aspects involved in its analysis, as well as its reciprocal and intrinsic influences. Currently, there is growing acknowledgement of the importance of epileptic manifestations during sleep, the relationship between sleep and QL in patients with epilepsy and the relevance of primary sleep pathologies on seizure control. ${ }^{(51)}$ Several factors are thought to contribute to inadequate seizure control in JME patients, including resistance to AEDs, neuropsychiatric comorbidity, and poor lifestyle choices. ${ }^{(24)}$

Comorbid anxiety and depression in JME patients adversely affects QL, ${ }^{(52)}$ because seizures in public places reduce social interaction and compromise the quality of interpersonal relationships. Nevertheless, there are materials showing depressive disorders even in patients with controlled seizures. ${ }^{(53)}$ Such inevitable depression results in SDs.

The comorbid SDs have negative effects on daytime behavior and academic performance in children and adolescents. ${ }^{(16,54,55)}$ This leads to untimely and irregular intake of AEDs.

Decrease in the frequency and severity of seizures depends on the patient, who in turn adheres to the sleepwakefulness regime and who avoids strong emotional shocks and other behaviors that might cause stress. ${ }^{(32)}$ So patients should know about the risk of seizure recurrence after sleep deprivation. ${ }^{(3)}$ Identifying and treating SDs and understanding the effect of circadian rhythms on JME can improve QL and control of seizures.

In conclusion, the available evidence indicates a distinct sleep pattern in JME. However, many questions remain to be answered regarding the relationship between SDs and JME, because SDs in JME are etiologically heterogeneous. At the same time, sleep problems in epileptic patients are important as an essential component in JME management. Therefore, this problem requires further and extensive investigation.

\section{Competing interests}

The authors declare that they have no competing interests.

\section{References}

1. Brain Basics: Understanding Sleep. Office of Communications and Public Liaison, National Institute of Neurological Disorders and Stroke, US National Institutes of Health, Bethesda. 2017 Available from: https://www.ninds.nih. gov/Disorders/Patient-Caregiver-Education/UnderstandingSleep.

2. Sleep-wake cycle: its physiology and impact on health. National Sleep Foundation. 2006. Available from: www. sleepfoundation.org.

3. Schmitt B. Sleep and epilepsy syndromes. Neuropediatrics. 2015; 46(3): 171-80. doi: 10.1055/s-0035-1551574.

4. Grigg-Damberger MM, Ralls F. Sleep disorders in adults with epilepsy: past, present, and future directions. Curr Opin Pulm Med. 2014;20(6):542-9. doi: 10.1097/ MCP.0000000000000101.

5. Malow BA, Vaughn BV. Treatment of sleep disorders in epilepsy. Epilepsy Behav. 2002; 3(5S):35-37.

6. O'Muircheartaigh J, Vollmar C., Barker GJ, Kumari V, 
Symms MR, Thompson P, et al. Abnormal thalamocortical structural and functional connectivity in juvenile myoclonic epilepsy. Brain. 2012;135(Pt 12):3635-44. doi: 10.1093/brain/ aws296.

7. Dennis GJ. The relationship between sleep and epilepsy. ACNR. 2016;16(2):13-16.

8. Wandschneider B, Thompson PJ, Vollmar C, Koepp MJ. Frontal lobe function and structure in juvenile myoclonic epilepsy: a comprehensive review of neuropsychological and imaging data. Epilepsia. 2012;53(12):2091-8. doi: 10.1111/epi.12003.

9. Shahnaz, Sher K, Abdul Sattar R. Clinical and EEG characteristics of juvenile myoclonic epilepsy. Pak J Med Sci. 2014; 30(1):12-5. doi: 10.12669/pjms.301.4465.

10. Lee JM, Kim SY, Hwang YH, Lee HW, Suh CK, Park SP. [Longitudinal assessment of cognitive function in patients with juvenile myoclonic epilepsy]. J Korean Epilepsy Soc. 2008;12(2):85-91. [Articke in Korean].

11. Motamedi M, Nasergivehch S, Karamghadiri N, Noroozian M. Juvenile myoclonic epilepsy (JME): neuropsychological profile and related factors with cognitive dysfunction. Iran $\mathrm{J}$ Psychiatry. 2014;9(1):14-19.

12. Gunatilake SB, Seneviratne SL. Juvenile myoclonic epilepsy: a study in Sri Lanka. Seizure. 2000;9(3):221-3.

13. Panayiotopoulos CP, Obeid T, Tahan AR. Juvenile myoclonic epilepsy: a 5-year prospective study. Epilepsia. 1994;35(2):285-96.

14. Aliberti V, Grünewald RA, Panayiotopoulos CP, Chroni E. Focal electroencephalographic abnormalities in juvenile myoclonic epilepsy. Epilepsia. 1994;35(2):297-301.

15. Jain SV, Kothare SV. Sleep and Epilepsy. Semin Pediatr Neurol. 2015;22(2):86-92. doi: 10.1016/j.spen.2015.03.005.

16. Roshan S, Puri V, Chaudhry N, Gupta A, Rabi SK. Sleep abnormalities in juvenile myoclonic epilepsy-A sleep questionnaire and polysomnography based study. Seizure. 2017;50:194-201. doi: 10.1016/j.seizure.2017.06.021.

17. Gigli GL, Calia E, Marciani MG, Mazza S, Mennuni G, Diomedi M, et al. Sleep microstructure and EEG epileptiform activity in patients with juvenile myoclonic epilepsy. Epilepsia. 1992;33(5):799-804.

18. Ramachandraiah CT, Sinha S, Taly AB, Rao S, Satishchandra P. Interrelationship of sleep and juvenile myoclonic epilepsy (JME): a sleep questionnaire-, EEG-, and polysomnography (PSG)-based prospective case-control study. Epilepsy Behav. 2012;25(3):391-6. doi: 10.1016/j. yebeh.2012.08.009.

19. Krishnan P, Sinha S, Taly AB, Ramachandraiah CT, Rao S, Satishchandra P. Altered polysomnographic profile in juvenile myoclonic epilepsy. Epilepsy Res. 2014;108(3):45967. doi: 10.1016/j.eplepsyres.2013.12.007.

20. Giorgi FS, Guida M, Caciagli L, Pagni C, Pizzanelli $\mathrm{C}$, Bonanni E, et al. Social cognition in juvenile myoclonic epilepsy. Epilepsy Res. 2016;128:61-67. doi: 10.1016/j. eplepsyres.2016.10.017.

21. Lin JJ, Dabbs K, Riley JD, Jones JE, Jackson DC, Hsu DA, et al. Neurodevelopment in new-onset juvenile myoclonic epilepsy over the first 2 years. Ann Neurol. 2014;76(5):660-8. doi: 10.1002/ana.24240.

22. Kim JH, Lee JK, Koh SB, Lee SA, Lee JM, Kim SI, Kang JK. Regional grey matter abnormalities in juvenile myoclonic epilepsy: a voxel-based morphometry study. Neuroimage. 2007;37(4):1132-7.

23. Fukuda A, Funari MP, Fernandes PT, Guerreiro CM, Li LM. Circadian rhythm and profile in patients with juvenile myoclonic epilepsy and temporal lobe epilepsy. Arq Neuropsiquiatr. 2015;73(1):3-6. doi: 10.1590/0004282X20140190.

24. Leahy T, Hennessy MJ, Counihan TJ. The "Cinderella Syndrome": A narrative study of social curfews and lifestyle restrictions in juvenile myoclonic epilepsy. Epilepsy Behav. 2017;78:104-108. doi: 10.1016/j.yebeh.2017.10.024.

25. England MJ, Liverman CT, Schultz AM, Strawbridge LM. Epilepsy across the spectrum: promoting health and understanding. A summary of the Institute of Medicine report. Epilepsy Behav. 2012;25(2):266-76. doi: 10.1016/j. yebeh.2012.06.016.

26. Shen Y, Zhang M, Wang Y, Wang L, Xu X, Xiao G, et al. Subjective sleep disturbance in Chinese adults with epilepsy: Associations with affective symptoms. Epilepsy Res. 2017;135:150-157. doi: 10.1016/j.eplepsyres.2017.06.014

27. Janz D, Christian W. Impulsive petit-mal. Deutsche Zeitschrift für Nervenheilkunde 176:346-386. (English translation by Genton P. 1994). In: Malafosse A, Genton P, Hirsch E, Marescaux C, Broglin D, Bernasconi M. (eds.) 1994;1957:229-251.

28. de Araujo Filho GM, Yacubian EM. Juvenile myoclonic epilepsy: psychiatric comorbidity and impact on outcome. Epilepsy Behav. 2013;28 Suppl 1:S74-80. doi: 10.1016/j. yebeh.2013.03.026.

29. Camfield CS, Camfield PR. Juvenile myoclonic epilepsy 25 years after seizure onset: a population-based study. Neurology. 2009;73(13):1041-5. doi: 10.1212/WNL.0b013e3181b9c86f. 30. Caplan R, Siddarth P, Gurbani S, Hanson R, Sankar R, Shields WD. Depression and anxiety disorders in pediatric epilepsy. Epilepsia. 2005;46(5):720-30.

31. Somayajula S, Vooturi S, Jayalakshmi S. Psychiatric disorders among 165 patients with juvenile myoclonic epilepsy in India and association with clinical and sociodemographic variables. Epilepsy Behav. 2015;53:37-42. doi:10.1016/j. yebeh.2015.09.024

32. Moskaleva PV, Shilkina OS, Artyukhov IP, Strotskaya IG, Dmitrenko DV, Shnayder NA. Nonpsychotic psychiatric disorders in juvenile myoclonic epilepsy. International Journal of Biomedicine. 2017;7(2):85-90. doi: 10.21103/Article7(2)_RA1.

33. Delgado-Escueta AV, Koeleman BP, Bailey JN, Medina MT, Durón RM. The quest for juvenile myoclonic epilepsy genes. Epilepsy Behav. 2013; 28 Suppl 1:S52-7. doi: 10.1016/j. yebeh.2012.06.033.

34. Sammaritano M, Sherwin A. Effect of anticonvulsants on sleep. Neurology. 2000;54(5 Suppl 1):S16-24.

35. Vaughn BV, D’Cruz OF, Beach R, Messenheimer JA. Improvement of epileptic seizure control with treatment of obstructive sleep apnea. Seizure. 1996;5(1):73-8.

36. Foldvary-Schaefer N. Sleep complaints and epilepsy: the role of seizures, antiepileptic drugs and sleep disorders. J Clin Neurophysiol. 2002;19(6):514-21.

37. Roder-Wanner UU, Noachter S, Wolf P. Response of polygraphic sleep to phenytoin treatment for epilepsy. A longitudinal study of immediate short and long-term effects. Acts Neurol Scand. 1987;76(3):157-67.

38. Wolf P, Roder-Wanner UU, Brede M. Influence of therapeutic phenobarbital and phenytoin medication on the polygraphic sleep of patients with epilepsy. Epilepsia.1984; 25(4):467-75.

39. Sabatowski R, Gálvez R, Cherry DA, Jacquot F, Vincent E, Maisonobe P, Versavel M; 1008-045 Study Group. Pregabalin reduces pain and improves sleep and mood disturbances in patients with post-herpetic neuralgia: results of a randomized, placebo-controlled trial. Pain. 2004;109(1-2):26-35. 
40. Gigli GL, Placidi F, Diomedi M, Maschio M, Silvestri G, Scalise A, Marciani MG. Nocturnal sleep and daytime somnolence in untreated patients with temporal lobe epilepsy: changes after treatment with controlled release carbamazepine. Epilepsia. 1997;38(6):696-701.

41. Copinschi G, Van Onderbergen A, L'Hermite-Balériaux M, Szyper M, Caufriez A, Bosson D, et al. Effects of shortacting benzodiazepine triazolam, taken at bedtime on circadian and sleep-related hormonal profiles in normal men. Sleep. 1990;13(3):232-44.

42. Sammaritano M, Sherwin AL. Effects of anticonvulsants on sleep. In: Bazil CW, Malow BA, Sammaritano MR, editors. Sleep and epilepsy: the clinical spectrum. Amsterdam: Elsevier; 2002:187-194.

43. Brodie MJ. Modern management of juvenile myoclonic epilepsy. Expert Rev Neurother. 2016;16(6):681-8. doi: 10.1080/14737175.2016.1179113.

44. Nayak CS, Sinha S, Nagappa M, Kandavel T, Taly AB. Effect of valproate on the sleep microstructure of juvenile myoclonic epilepsy patients - a cross-sectional CAP based study. Sleep Med. 2016;17:129-33. doi: 10.1016/j. sleep.2015.11.006.

45. Guilleminault C. Benzodiazepines, breathing, and sleep. Am J Med. 1990; 2;88(3A):25S-28S.

46. Baykan B, Martínez-Juárez IE, Altindag EA, Camfield CS, Camfield PR. Lifetime prognosis of juvenile myoclonic epilepsy. Epilepsy Behav. 2013;28 Suppl 1:S18-24. doi: 10.1016/j.yebeh.2012.06.036

47. Artyukhov IP, Shilkina OS, Shnayder NA, Dmitrenko DV, Bochanova EN, Shapovalova EA, Strotskaya IG. Case report of management problem of juvenile myoclonic epilepsy. Case Rep Clin Med. 2016;5: 217-224. doi: 10.4236/ crcm.2016.57040.

48. Artyukhov IP, Shilkina OS, Shnayder NA, Dmitrenko DV, Bochanova EN, Babina IS. Paradigms of management of juvenile myoclonic epilepsy. Archiv Euromedica. 2016; 6(2): 2-7

49. Shilkina O, Petrov K, Diuzhakova A, Marueva N, Shnayder N. Frequency of juvenile myoclonic epilepsy clinical phenotypes in Siberia. World J Neurosci. 2016; 6:3236. doi: 10.4236/wjns.2016.61004

50. Shnayder NA, Shilkina OS, Petrov KV, Chernykh IA, Diuzhakova AV. [Clinical and genetic heterogenity of juvenile myoclonic epilepsy]. Epilepsia and Paroxyzmal Conditions. 2016;8(2):20-36. doi:10.17749/2077-8333.2016.8.2.020-036 [Article in Russian].

51. Rocamora R, Sánchez-Alvarez JC, Salas-Puig J. The relationship between sleep and epilepsy. Neurologist. 2008;14(6 Suppl 1):S35-43. doi: 10.1097/01.nrl.0000340790.15295.59 52. Kotov AS. [Anxiety in epileptic patients]. Zh Nevrol Psikhiatr Im SS Korsakova. 2013;113(4 Pt 2):41-4. [in Russian]. 53. Moschetta S, Valente KD. Impulsivity and seizure frequency, but not cognitive deficits, impact social adjustment in patients with juvenile myoclonic epilepsy. Epilepsia. 2013;54(5):866-70. doi: 10.1111/epi.12116.

54. Chan S, Baldeweg T, Cross JH. A role for sleep disruption in cognitive impairment in children with epilepsy. Epilepsy Behav. 2011;20(3):435-40. doi: 10.1016/j.yebeh.2010.12.047. 55. Parisi P, Bruni O, Pia Villa M, Verrotti A, Miano S, Luchetti A, Curatolo P. The relationship between sleep and epilepsy: the effect on cognitive functioning in children. Dev Med Child Neurol. 2010;52(9):805-10. doi: 10.1111/j.14698749.2010.03662.x. 